\title{
Conceitos e uso da informação organizacional e informação estratégica
}

\author{
Concepts and use of the organizational \\ information and strategic information
}

Angélica Toffano Seidel CALAZANS ${ }^{1}$

RESUMO

A informação é o alicerce da geração de conhecimento e por este motivo é considerada um dos mais importantes ativos organizacionais. Como um ativo, a informação precisa ser gerenciada e controlada. A gestão da informação, a forma como as organizações acessam, organizam, compartilham, fazem uso da informação e criam conhecimento é uma das importantes bases para a competitividade. Para utilizar de forma efetiva a informação interna e externa, a organização necessita gerenciá-la, identificando o fluxo informacional, fatores impactantes deste processo, tipos de informação existentes e necessárias para a agregação de valor. Neste trabalho são identificados e analisados os conceitos de organização, informação e sua evolução dentro de um contexto organizacional. São descritos conceitos de informação organizacional, informação estratégica e suas tipologias. São identificados, também, alguns dificultadores para o processo de gestão da informação, destacando a importância de análise do fluxo informacional para garantir a qualidade e eficácia da informação.

Palavras-chave: informação organizacional; informação estratégica; fluxo de informação; organização.

\begin{abstract}
A B STRACT
Information is the basis for knowledge generation and for this reason it is considered one of the most important issues within an organization. Like an asset, information needs to be managed and controlled. Information management, the manner in which organizations access, organize and share, make use of information and create knowledge, is an important basis for competitiveness. In order to effectively use inside and outside information, an organization must manage it, identify the information flow, the factors that impact their process, and the existing types of information which are necessary to the add value. In this work, organizations and information concepts are identified and analyzed, as well as noting their evolution within the organizational context. Definitions about organizational information, strategic information and the study of their types are described. Also, some aspects that hinder the information management process are identified, emphasizing the importance of informational flow analysis in order to ensure information quality and effectiveness.
\end{abstract}

Key words: organizational information; strategic information; information flow; organization.

I N T R O D U Ã O

Na atualidade o conhecimento e a informação são características dominantes. Em todos os campos (científico, técnico, social, comercial, organizacional e outros) encontramos tanto dimensões de conhecimento quanto de informação (SARACEVIC, 1999).

\footnotetext{
1 Professora, Instituto CEUB de Pesquisa, e Desenvolvimento, Formação Específica em Análise de Sistemas, Centro Universitário de Brasilia. SEPN 707/907, Campus do UniCEUB, Bloco XI, Asa Norte, 70790-075, Brasília, DF, Brasil. E-mail: <angelica_toffano@yahoo.com.br>. Recebido em 6/12/2005 e aceito para publicação em 17/2/2006.
} 
O uso da informação pelas organizações é considerado um dos recursos mais importantes para garantir a competitividade nos dias atuais. A informação é criada, tratada e transferida às organizações, sendo a eficiência desse processo a garantia do bom desempenho e do deslocamento da organização para patamares mais elevados de competitividade.

A informação organizacional possui características e dimensões específicas. Um de seus segmentos é a informação estratégica, que tem como principal objetivo o uso de dados, informação e conhecimento para agregação de valor a produtos e/ou serviços, garantindo a sobrevivência da organização aos desafios atuais.

A conceituação e definição do uso da informação organizacional e estratégica, permite um maior conhecimento do ambiente informacional e da sua gestão, identificando características, funcionalidades, necessidades e valores.

\section{Informação}

O termo informação foi definido por vários autores de muitas áreas do conhecimento: Drucker (1999) conceitua informação como dados organizados dotados de significado, Miranda (1999) complementa esta definição afirmando que a informação é composta de dados organizados significativamente para subsídiar a tomada de decisão. Davenport (1998) define a informação como um termo que engloba dados, informação e conhecimento, abrangendo também a conexão entre os dados e o conhecimento obtido.

A informação tem evoluído através e junto com a história, modificando significados e impactando indivíduos, sociedades e organizações. A humanidade está vivenciando a quarta revolução da informação na história. A primeira foi a invenção da escrita (há aproximadamente 6 mil anos) e a segunda foi a do livro escrito (China em 1300 a.C.); sobre estas duas revoluções há poucas evidências do impacto social efetuado. A terceira revolução da informação foi causada pela invenção da imprensa e do tipo móvel por Gutenberg (entre 1450 e 1455) e, diferentemente das outras, é possível identificar os seus impactos. Em pouco tempo a revolução da imprensa mudou instituições e o sistema de ensino, definindo o ensino universal, ou seja, a escola de hoje. Tornou possível a reforma protestante e várias outras modificações na sociedade, ensino e cultura (DRUCKER, 1999).

A quarta revolução da informação, que está em andamento, vem ocorrendo nos últimos 50 anos. Baseada na imprensa, caracteriza-se pelo crescimento exponencial de livros e revistas, nos variados campos e interesses. Sua finalidade dessas publicações não é o entretenimento nem a educação, mas a informação (DRUCKER, 1999). A possibilidade da utilização dos canais eletrônicos, neste contexto, tende a aprofundar, ainda mais, as mudanças do significado da informação tanto para os indivíduos como para as organizações.

A informação para as organizações está se tornando um ativo que pode ser comparável a outros tipos de ativo como capital, propriedade, recursos humanos, bens materiais e, como tais, necessita ser gerenciada (McGEE e PRUSAK, 1994). Gerenciar este ativo, de forma a tornar a informação útil para que as pessoas possam atuar com eficácia e garantir a competitividade organizacional, tem sido um grande desafio.

\section{Organização}

O termo organização possui diversas definições que abrange variadas áreas do conheci-mento, tais como: Administração, Economia, Ciência da Informação, etc. Barnard (1938) foi um dos primeiros autores a definir o termo organização como um sistema de atividades coordenadas conscientemente. Robbins (1983) aprofundou a definição proposta por Barnard (1938) e apresentou a visão de organização como o planejamento coordenado de um conjunto de atividades nas quais duas ou mais pessoas trabalham continuamente afim de atingirem um ou mais objetivos comuns, divi-dindo os esforços e com definições de autoridade. Moresi (2001a, p.59) define "organização como um agrupamento humano planejado e organizado, que utiliza a tecnologia disponível no ambiente para atingir um ou mais objetivos comuns".

Outra visão de organização é a que a considera um sistema complexo sob diversas perspectivas: finanças (relacionando seus fluxos financeiros), sob o ângulo de pessoas (analisando suas motivações, inter relacionamentos), na perspectiva da produção 
(visão de transformar insumos em produtos) (HENRIQUE; BARBOSA, 2005), e também sob a perspectiva da informação (analisando os fluxos, a necessidade informacional, etc.).

Qualquer que seja a definição ou visão do conceito informação, os termos conjunto de pessoas, atividades e objetivos comuns estão presentes em quase todas as definições. A forma como as organizações atuam, tanto na cultura organizacional quanto na estrutura organizacional e seus inter relacionamentos, é que estão se modificando constantemente, até mesmo o seu relacionamento com a informação.

Na primeira metade do século XX e na época pós-guerras, a cultura das organizações era totalmente orientada à produção, ou seja, o principal objetivo era produzir, aumentando a eficiência e a produtividade. Algumas teorias da organização e direção de empresas desta época (Organização cientifica do trabalho, Escola Administrativa de Fayol, Modelo Burocrático de Max Weber) reforçavam a idéia de produtividade e eficiência, sem considerar as mudanças externas e outros aspectos. Nesta época, toda a produção era vendida, não importando características como: as necessidades do cliente, a qualidade, e a necessidade informacional (AGUILLO, 1999).

O excesso da oferta, o avanço tecnológico a competência da concorrência, as maiores exigências dos clientes, as mudanças da estrutura de consumo, as mudanças sociais (mudanças na distribuição de renda, etc.) e demográficas (taxa de natalidade em queda no mundo desenvolvido, imigração, etc.) e a globalização econômica foram alguns fatores que modificaram este cenário. No século XXI, as organizações devem ser capazes de atrair, satisfazer e reter os clientes produzindo de forma mais rápida, barata e com qualidade. E neste contexto, a informação passou a ser considerada um dos mais importantes ativos a ser preservado e gerenciado nas organizações.

Para Valentim (2002), as organizações são formadas por três diferentes ambientes: o primeiro é formado pelas inter-relações entre as diferentes unidades de trabalho como diretorias, gerencias, divisões, departamentos, setores, seções, etc. (organograma); o segundo está relacionado as relações entre pessoas das diferentes unidades de trabalho (estrutura de recursos humanos) e o terceiro é composto pela estrutura informacional, ou seja, geração de dados, informação e conhecimento pelos dois ambientes anteriores.

\section{Informação organizacional}

O uso da informação nas organizações, obviamente, acompanhou a evolução das organizações. Considerada inicialmente um requisito burocrático necessário, que contribuía para reduzir o custo do processamento de muitos papéis (anos 50), a informação foi utilizada posteriormente como um suporte de auxilio ao gerenciamento de diversas atividades. A partir das décadas de 70 e 80, passou a ser compreendida como um fator de controle e gerenciamento para toda a organização e para ajudar os processos de tomada de decisão. Da década de 90 até os dias atuais a informação começou a ser reconhecida como um recurso estratégico, fonte de vantagem competitiva para garantir a sobrevivência da empresa(MORAES; TERENCE; ESCRIVÃO FILHO, 2004).

Para Davenport (1998), a gestão da informação em uma organização envolve quatro diferentes abordagens de fluxo: informação não estruturada (fontes impressas, livros, jornais e relatórios, rumores), informação estruturada em papel (registros, documentos), a informação estruturada em computadores e o capital intelectual ou conhecimento (baseada no conhecimento dos funcionários). Esses fluxos se sobrepõem e a influência de cada um deles varia de acordo com a época; na década de 70 a ênfase era na informação estruturada em computadores e na década de 90 na adminis-tração do conhecimento.

Valentim (2002) cita como fontes de informação organizacional o que Davenport (1998) considera fluxos de informação. Valentim (2002) classifica as fontes de informação em: dados, informação e conhecimento estruturados (compostos de bancos e bases de dados internos e externos, redes de comunicação como intranet, Internet e publicações impressas), dados, informação e conhecimento Estruturáveis (produzidos pelos diversos setores da organização, porém sem seleção, tratamento e acesso) e Dados, Informações e Conhecimento não estruturados (produzidos externamente a organização, porém sem filtragem e tratamento).

Segundo Choo (2003), a informação desempenha um papel estratégico no crescimento e na capacidade organizacional e existem três campos para 
sua criação e uso: a organização utiliza a informação para entender as mudanças do ambiente externo e se adaptar de forma mais rápida, a organização cria, organiza e processa a informação de modo a gerar novos conhecimentos por meio do aprendizado, criando novos produtos ou serviços, e a organização busca e avalia a informação de modo a identificar alternativas plausíveis, prováveis resultados e avaliar o impacto desses para a organização.

As informações, os fluxos e as fontes de informação precisam ser gerenciadas e organizadas de maneiras diferentes para atender às várias finalidades organizacionais, ter significado e gerar conhecimento organizacional.

\section{Classificação da informação organizacional}

As organizações estão começando a compreender como produzir e utilizar a informação dos mais variados modos, e Drucker (1999) classifica as informações organizacionais em grupos de interesse voltados para: produção de controle (contabilidade de custos), conhecimento dos custos de sua cadeia econômica (realidade econômica), para criação de riqueza que englobariam informações básicas, produtividade, competência, alocação de recursos e informações organizadas do ambiente (mercado, finanças mundial, não clientes, etc.).

Valentim (2002) amplia a definição de Drucker (1999) e classifica as informações organizacionais em: estratégicas, de mercado, financeiras, comerciais, estatísticas, de gestão, tecnológicas, gerais e cinzentas (de qualquer natureza, para qualquer área e com qualquer finalidade de uso, que não são detectados em buscas formais de informação, como por exemplo: memória das pessoas, documentos confidenciais de difícil acesso, etc.).

Moresi (2001a) complementa com outra dimensão, as propostas de Drucker (1999) e Valentim (2002), quando classifica as informa-ções quanto aos diferentes níveis organizacionais: informação de nível institucional destinada a subsidiar o planejamento e as decisões de alto nível, informação de nível intermediário que permite a avaliação dos processos, o planejamento e a tomada de decisão de nível gerencial e informação de nível operacional que subsidia o planejamento e a tomada de decisão de nível operacional. Moresi (2001b) ainda classifica a informação organizacional quanto ao seu status de importância: informação crítica, mínima, potencial e sem interesse, cabendo a organi-zação potencializar seus esforços para preservar a informação crítica, mínima e potencial (nesta ordem).

Dias e Belluzzo (2003) consolidam parte destes conceitos no Quadro 1 em que apresentam a informação organizacional distribuída em quatro contextos: Classificação, Dimensão, Objetivos e Fontes. O Quadro foi adaptado para incluir a contribuição de Drucker (1999), Valentim (2002) e Moresi (2001a).

Analisando o Quadro 1, pode-se concluir que independente de sua classificação, dimensão, objetivo ou fonte, a informação organizacional pode possuir diferentes visões de valor. Para Beal (2004) a informação é um fator de sinergia quando a organização possui um fluxo informacional eficiente e proporciona o intercâmbio de idéias e informações. A informação é também um fator determinante do comportamento, pois influencia o comportamento dos indivíduos e dos grupos, dentro e fora das organizações.

A informação possibilita a redução da incerteza na tomada de decisão, permitindo que escolhas sejam feitas com menor risco e no momento adequado, e é um elemento importante para se criar e introduzir produtos (bens ou serviços) no mercado, o que seria um dos principais objetivos da informação estratégica organizacional.

\section{Informação estratégica}

O termo estratégia deriva da expressão grega strategos, que significa a "arte do general". O estrategista, como comandante militar, tinha e tem por responsabilidade dirigir as forças militares durante um conflito, planejando e executando movimentos para alcançar ou manter a supremacia frente ao oponente, aumentando, assim, a chance de vitória. O significado do termo ampliou-se, mas sua essência não modificou substancialmente. Nas organizações, os estrategistas ou gestores organizacionais de alto escalão devem promover os produtos ou serviços de forma a garantir a supremacia da organização frente às concorrentes.

Na década de 90, Porter (1996) definia estratégia como a realização de um conjunto de atividades com o objetivo de agregar maior valor para os clientes e/ou um valor semelhante ao de mercado a um custo 
Quadro 1. Informação no contexto organizacional.

\begin{tabular}{|c|c|c|c|}
\hline Classificação & Dimensões & Objetivos & Fontes \\
\hline $\begin{array}{l}\text { Quanto à natureza } \\
\text { - Informação científica } \\
\text { (Resultante da investigação científica) } \\
\text { - Informação tecnológica } \\
\text { (Relacionada aos produtos e serviços } \\
\text { e seus mercados) }\end{array}$ & $\begin{array}{l}\text { Formato } \\
\text { - Oral x documental } \\
\text { - Textual x audiovisual } \\
\text { - Base papel x base eletrônica }\end{array}$ & $\begin{array}{l}\text { Pesquisa } \\
\text { - Monitoramento do mer- } \\
\text { cado e conhecimento das } \\
\text { descobertas e inovações } \\
\text { - Análise de tendências e } \\
\text { de mercado }\end{array}$ & $\begin{array}{l}\text { - Bases e banco de dados } \\
\text { - Bases de patentes } \\
\text { - Bases de normas técnicas } \\
\text { - Literatura científica } \\
\text { - Relatórios técnicos, teses e } \\
\text { pesquisas }\end{array}$ \\
\hline $\begin{array}{l}\text { Quanto à função } \\
\text { - Informação estratégica } \\
\text { (Relacionada ao micro e macro } \\
\text { ambiente organizacionais) }\end{array}$ & $\begin{array}{l}\text { Local } \\
\text { - Interna x externa }\end{array}$ & $\begin{array}{l}\text { - Tomada de decisão/ge- } \\
\text { renciamento/ resolução } \\
\text { de problemas } \\
\text { - Avaliação do estado da }\end{array}$ & $\begin{array}{l}\text { - Documentos internos } \\
\text { - Manuais técnicos } \\
\text { - Literatura comercial } \\
\text { - Leis, regulamentos e códigos }\end{array}$ \\
\hline $\begin{array}{l}\text { Informação para negócios } \\
\text { (Subsidia o gerenciamento das } \\
\text { organizações) }\end{array}$ & $\begin{array}{l}\text { Nível } \\
\text { - Informação bruta } \\
\text { - Informação organizada } \\
\text { - Informação tratada } \\
\text { - Informação avançada }\end{array}$ & $\begin{array}{l}\text { arte } \\
\text { - P\&D de processos e } \\
\text { produtos } \\
\text { Melhoria contínua } \\
\text { - Definição de objetivos, }\end{array}$ & $\begin{array}{l}\text { - Estatísticas e indicadores eco- } \\
\text { nômicos e empresariais } \\
\text { - Cadastros de especialistas } \\
\text { - Publicações governamentais } \\
\text { - Organizações científicas e insti- } \\
\text { tutos de pesquisa }\end{array}$ \\
\hline $\begin{array}{l}\text { Quanto aos diferentes níveis } \\
\text { organizacionais } \\
\text { - nível institucional } \\
\text { - nível intermediário } \\
\text { - nível operacional }\end{array}$ & $\begin{array}{l}\text { Status } \\
\text { - Pessoal ximpessoal } \\
\text { - Formal x informal } \\
\text { - Publicação aberta x não } \\
\text { publicada }\end{array}$ & $\begin{array}{l}\text { metas, mercado } \\
\text { - Memória técnica } \\
\text { - Instrução e treinamento } \\
\text { - Processo operacional }\end{array}$ & $\begin{array}{l}\text { - Serviços de informação, bi- } \\
\text { bliotecas, centros de documen- } \\
\text { tação } \\
\text { - Sistemas especialistas }\end{array}$ \\
\hline $\begin{array}{l}\text { Quanto ao tipo } \\
\text { - mercado } \\
\text { - financeiras } \\
\text { - comerciais } \\
\text { - estatísticas } \\
\text { - gestão } \\
\text { - tecnológicas } \\
\text { - gerais }\end{array}$ & $\begin{array}{l}\text { Status de importância } \\
\text { - crítica } \\
\text { - mínima } \\
\text { - potencial } \\
\text { - sem interesse }\end{array}$ & & \\
\hline
\end{tabular}

Adaptado de Dias e Belluzzo (2003).

mais baixo. A estratégia competitiva de uma empresa define suas atividades comerciais, a forma de operar e diferenciar os produtos e serviços dos oferecidos pelos concorrentes (McGEE; PRUSAK ,1994).

Para executar esta tarefa, os estrategistas necessitam de informações que possibilitem tomadas de decisões fundamentadas, informação correta, em tempo hábil e no local adequado. Segundo McGee e Prusak (1994), a capacidade de adquirir, interpretar e utilizar a informação de forma eficaz poderá garantir, na economia da informação, a diferenciação. Ou seja, a gestão da informação será, cada vez mais, a base para a competitividade. Nas instituições financeiras, a informação tornou-se uma questão estratégica, onde o objetivo é melhorar o retorno dos investimentos a partir dos dados gerenciados e manipulados. Entretanto, menor atenção tem sido devotada à possibilidade de obter valor estratégico por meio do gerenciamento aperfeiçoado de uma informação que é mais qualitativa e difundida por toda organização.

Algumas características da informação dificultam a gestão para a criação, distribuição e uso da informação estratégica: a informação pode surgir de várias formas (explícita, implícita, etc.); existe escassez de informação correta; é difícil criar informação; é fácil reproduzi-la; a informação não se deprecia da mesma forma que os bens de capital, seu valor pode ser eterno ou perecível (dependendo das circunstancias); o valor da informação aumenta com o uso e com a precisão (McGEE; PRUSAK, 1994; BEAL, 2004).

A informação estratégica impacta e é influenciada por muitos conceitos. A Figura 1, demonstra o modelo mental dos conceitos e fatores vinculados à informação estratégica, elaborado por Miranda (1999) e adaptado pela autora. 
Um dos conceitos que influenciam diretamente a informação organizacional e, consequentemente, a informação estratégica é o fluxo informacional. Segundo Krovi, Chandra e Rayagopalan (2003) as organizações necessitam empreender esforços sistemáticos e conscientes para influenciar e controlar o fluxo da informação para promover um processo de negócio eficiente no ambiente organizacional.

O fluxo informacional é responsável pela qualidade da informação, sua distribuição e adequação da informação às necessidades do usuário. A gestão da informação organizacional é realizada através da coordenação, administração e planejamento do ambiente informacional e dos seus fluxos de informação. Davenport (1998) identifica quatro fases para o processo de gerenciamento da informação: determinação das exigências, obtenção da informação, distribuição e utilização da informação. Choo (2003, p. 404) define as seguintes fases do fluxo informacional organizacional: "identificação das necessidades informacionais, aquisição da informação, organização e armazenagem da informação, desenvolvimento de produtos informa-cionais e serviços, distribuição da informação e uso". O modo como o fluxo informacional é implementado na organização também influencia a informação estratégica e na Figura 1 foi acrescentada esta característica ao modelo mental proposto por Miranda (1999).

A complexidade que envolve a informação estratégica e a dificuldade de sua gestão é decorrente, também, dos vários níveis envolvidos para sua obtenção - do nível individual ao interorganizacional (McGEE; PRUSAK, 1994, p. 71).

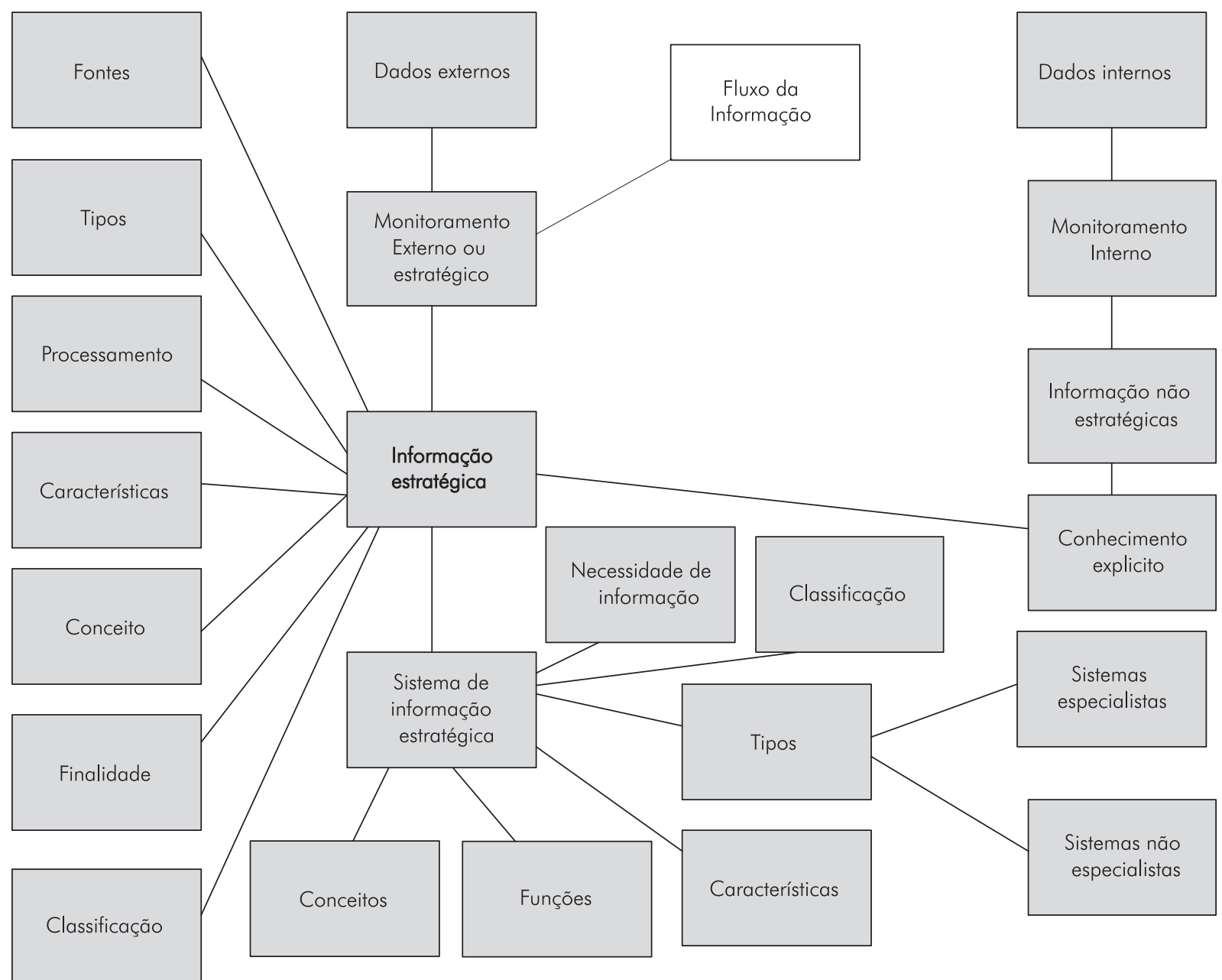

Figura 1. Modelo mental da Informação estratégica.

Fonte: Adaptado de Miranda (1999). 
Miranda (1999) identifica alguns tipos de informação estratégica, entre eles:

- cliente: dados sobre comportamentos de consumo, nível de qualidade requerido, perfil, etc.;

- concorrente: abrangendo perfil dos concorrentes, a imagem no mercado, preços praticados e prazos concedidos, faturamento, qualidade dos produtos e serviços ofertados, etc.;

- cultural: informações sobre educação (grau de alfabetização, níveis de escolaridade), acesso aos meios de comunicação (TV, rádio, periódicos, internet), hábitos culturais (teatro, cinema, exposições - pintura, escultura, etc.);

- demográfica: abrangendo dados da população (idade, sexo, raça, cor, área geográfica, nível de renda, crença religiosa), índices de natalidade e de mortalidade (geral e infantil), a expectativa de vida da população, as taxas de crescimento demográfico-vegetativo, etc.;

- econômica/financeira: informações sobre a conjuntura econômica nacional e mundial, a atuação de blocos econômicos e segmentos de mercado (Mercosul), a balança comercial e de pagamentos, a taxa de juros, tarifas de prestação de serviços, planos econômicos, etc.;

- fornecedor - informações sobre o perfil, atitudes, localização, preços, prazos de pagamento, descontos, entrega, etc.;
- política/governamental - dados e informações sobre regulamentações, desregula-mentações, políticas fiscais, de importação, de exportação, habitacional, salarial e de privatizações, relações internacionais, planos de governo);

- outros.

Pode-se acrescentar, neste contexto, a informação sobre produtos/serviços da organização, com dados sobre a aceitação do produto/serviço, vendas, evolução e projeção de cenários futuros que viriam a agregar maior eficácia a informação estratégica. A informação estratégica, independente dos tipos necessários para sua composição, está inserida no ambiente informacional da organização e deve ser gerenciada assim como os outros tipos de informação (Figura 2).

A estratégia competitiva de uma organização é composta de um mapa de informações que responde a perguntas sobre a maneira pela qual a empresa irá operar no mundo. Este mapa permite identificar a informação estratégica que a empresa precisa ter e a forma de utilizá-la mais eficiente possível, permite definir as maneiras de tornar os produtos/serviços de uma empresa superiores aos de seus concorrentes e identifica também a informação que a organização precisa fornecer a seus clientes e

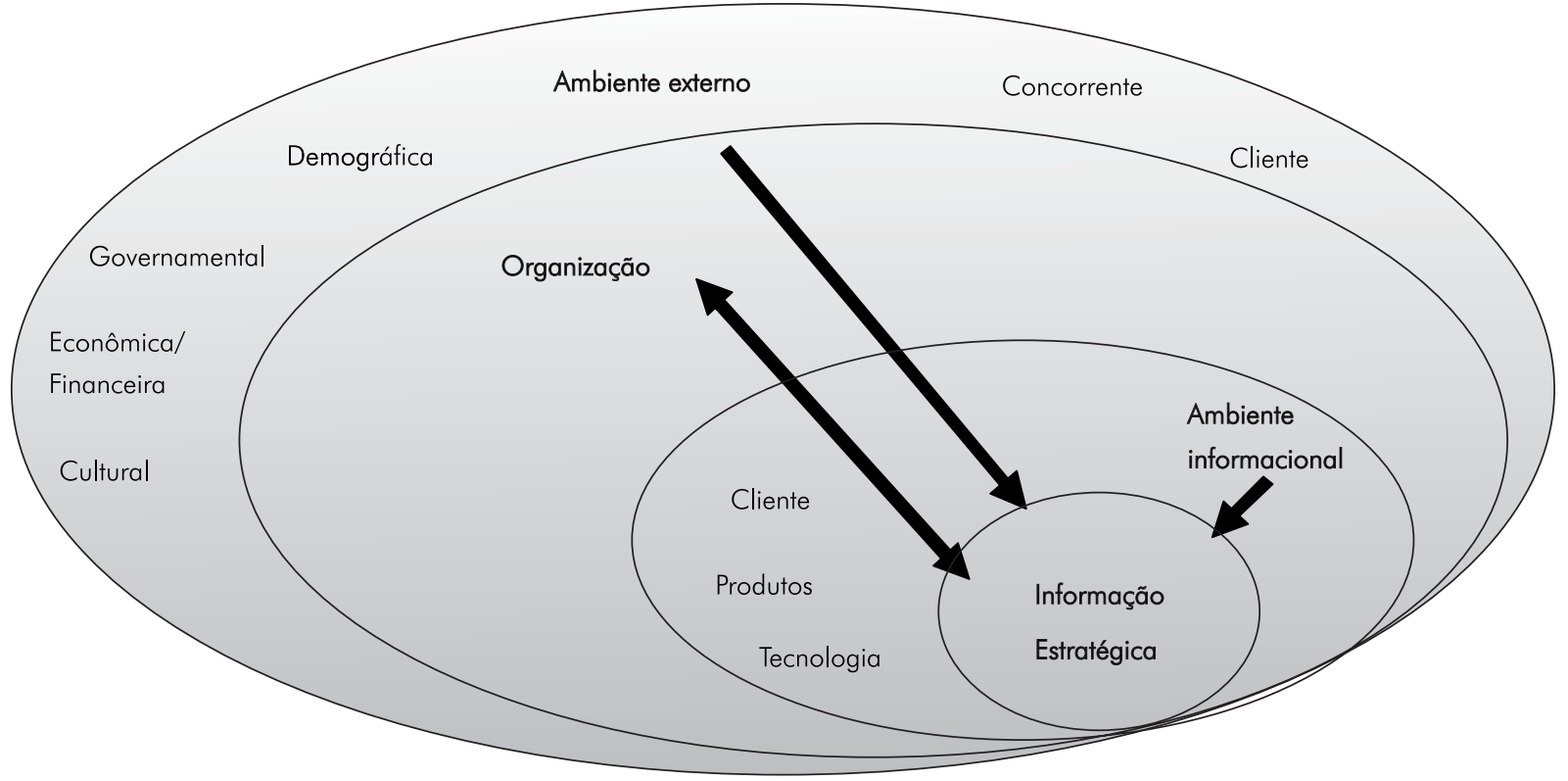

Figura 2. Contexto da informação estratégica. 
fornecedores, como incorporar esta informação aos seus produtos e serviços e fornecer a organização a habilidade de responder rapidamente as demandas do consumidor final (McGEE; PRUSAK ,1994).

\section{O N CLUS Ã O}

A importância da informação para as organizações já é universalmente aceita e é considerada um dos recursos mais importantes para o sucesso. Mas, para que ocorra sua gestão efetiva, no ambiente organizacional, é necessário a percepção dos valores da informação (MORESI, 2001b). A informação, no contexto organizacional, é utilizada para agregar valor tanto internamente como externamente, garantindo a sobrevivência e a competitividade. Porém, para que a informação seja eficaz ela necessita ser administrada e gerenciada.

\section{REFERÊNCIAS}

AGUILLO, C. Câmbios significativos em el mundo empresarial. Economia Industrial, n. 330, p.11-18, 1999.

BARNARD, C.I. The Functions of the executive. Cambridge, Mass: Harvard University Press, 1938. p.73.

BEAL, A. Gestão estratégica da informação: como transformar a informação e a tecnologia da informação em fatores de crescimento e de alto desempenho nas organizações. São Paulo: Atlas, 2004. p.22.

CHOO, C. A organização do conhecimento. São Paulo: Editora Senac, 2003. 425p.

DAVENPORT, T. Ecologia da informação: por que só a tecnologia não basta para o sucesso na era da informação. São Paulo: Futura, 1998. 316p.

DIAS, M.; BELLUZZO, R. Gestão da informação em ciência e tecnologia sob a ótica do cliente. Bauru: EDUSC, 2003. 184p.

DRUCKER, P. Desafios gerenciais para o século XXI. São Paulo: Pioneira, 1999. 168p.

HENRIQUE, L.; BARBOSA, R. Gestão da informação e do conhecimento organizacionais: em busca de uma heurística adaptada a cultura brasileira. Perspectivas em Ciência da Informação, v.10, n.1, p.4-17, 2005.

KROVI, R.; CHANDRA, A.; RAJAGOPALAN, B. Information Flow Parameters for Managing Organizational Processes. Communications of the ACM, v.46, n.2, p.77-82, 2003.
O principal objetivo da gestão da informação é identificar e potencializar os recursos informacionais de uma organização, ensinando-a a aprender e adaptar-se às mudanças ambientais, segundo Tarapanoff (2001).

Nesta pesquisa foram apontadas as principais características e dimensões da informação organizacional e da informação estratégica. Foram conceitualizados estes dois tipos de informação e detalhados os seus diferentes objetivos, características e aplicabilidades. Foi sugerida, também, a necessidade do estudo do fluxo informacional para assegurar qualidade e adequação das informações à necessidade do usuário e da organização. O estudo detalhado da captação, tratamento e comunicação do conteúdo informacional tornará o processo de disseminação de conhecimento da empresa mais eficaz.

empresa utilizando a informação como ferramenta estratégica. Rio de Janeiro: Campus, 1994.

MIRANDA, R. O uso da informação na formulação de ações estratégicas pelas empresas. Ciência da Informação, v.28, n.3, p.286-292, 1999.

MORAES, G.D.A.; TERENCE, A.C.F.; ESCRIVÃO FILHO, E. A tecnologia da informação como suporte à gestão estratégica da informação na pequena empresa. Revista de Gestão da Tecnologia e Sistemas de informação, v.1, n.1, p.27-43, 2004.

MORESI, E. O contexto organizacional. In: TARAPANOFF, K. (Org.). Inteligência organizacional e competitiva. Brasília: UnB, 2001a. p.59-91.

MORESI, E. Gestão da informação e do conhecimento. In: TARAPANOFF, K. (Org.). Inteligência organizacional e competitiva. Brasília: UnB, 2001b. p.111-142.

PORTER, M. What's strategy? Harvard Business Review, v.74, n.6, p.61-78, 1996.

ROBBINS, S.P. Organization theory: the structure and design of Organizations. New Jersey: Prentice-Hall Inc,1983. 560p.

SARACEVIC, T. Information science. Journal of the American Society for Information Science, v.50, n.12, p.1051-1063, 1999.

TARAPANOFF, K. Referencial teórico: introdução. In: TARAPANOFF, K. (Org.). Inteligência organizacional e competitiva. Brasília: UnB, 2001. p.33-58.

VALENTIM, M.L.P. Inteligência competitiva em organizações: dado, informação e conhecimento. Datagramazero-Revista da Ciência da Informação, v.3, n.4, p.1-23, 2002. 